No presente artigo, discute-se que um diagnóstico diferencial da psicose e do autismo deve superar a dicotomia organogênico/psicogênico, introduzir a incidência do discurso contemporâneo sobre o autismo e levar em conta a passagem do autismo para a psicose. Este diagnóstico assim formulado terá conseqüências clínicas sobre a direção do tratamento, em especial sobre a escuta dos pais. Aposta-se que, para eles, fará diferença que um psicanalista oponha resistência à objetalização da criança e à "desresponsabilização" do Outro materno. Autismo; diagnóstico; psicose infantil

PSYCHOSIS AND AUTISM: DIAGNOSTIC PROBLEMS

In this article, it is discussed bow a differential diagnosis of psychosis and autism should overcome the organogenicl psychogenic dicotomy as well as introduce the incidence of the contemporary speech about autism and take into consideration the grouth of autism into psychosis. This diagnosis will bave clinical consequences as regards treatment, especially when it comes to parents' listening. It is believed that, for them, it will make a difference if a psychoanalyst opposes resistence to the objetification of the child and to the "de-responsibilization" of the motherly Other.

Psychosis, autism, diagnosis.

\section{PSICOSE E \\ AUTISMO NA INFÂNCIA: PROBLEMAS DIAGNÓSTICOS}

$\left({ }_{s}\right.$ diagnósticos de psicose infantil e autismo têm uma história recente. Até o início deste século, o olhar médico ainda não os havia subtraído do grande grupo das crianças chamadas de deficientes mentais. Para a sociedade, todas as crianças daquele grande grupo estavam votadas ao cruel destino dos adultos doentes mentais: o diagnóstico de incuráveis e o conseqüente asilamento.

Na primeira terça parte deste século, porém, iniciaram-se as tentativas diagnósticas. O saber médico deu nomes às crianças que se destacavam do grande grupo das deficientes mentais. Sancte de Sanctis observou que, ao lado do rebaixamento, algumas crianças apresentavam "perturbações graves da atividade voluntária, tais como o negativismo, a tendência às ações rítmicas, a impulsividade" (citado por Postel \& Quétel, 1993, p.519), e criou para elas o diagnóstico de demência precocíssima. E, nesse grupo

Psicanalista, professora livre-docente do Instituto de Psicologia da USP, diretora da Pré-Escola Terapêutica Lugar de Vida. 
recortado do das deficiências, Kanner isolou ainda o autismo, em 1943. Para Kanner, as crianças autistas eram incapazes de estabelecer relações; as que tinham linguagem não a usavam para comunicar-se; possuíam uma excelente capacidade de memorização decorada, reagiam com horror a ruídos fortes ou objetos em movimento, tendiam à repetição, mas eram dotadas de boas potencialidades cognitivas.

O estabelecimento de diagnósticos trouxe consigo a esperança de um tratamento adequado àquelas patologias. Mas o que parecia tão promissor transformou-se, de fato, no início de uma querela em torno das origens desses males organogênese ou psicogênese? - que se desdobrou em uma inevitável discussão sobre o grau de participação das mães na instalação dos quadros - se a origem é orgânica, não são culpadas - e em um debate, mais recente e restrito ao campo da psicanálise, em torno do diagnóstico diferencial entre psicose e autismo.

Defender-se-á, no presente artigo, a posição segundo a qual é necessário, em primeiro lugar, sustentar um debate com o discurso médico em torno da etiologia dos distúrbios de desenvolvimento, e, em segundo lugar, sustentar o diagnóstico diferencial entre psicose e autismo, justamente porque tanto a questão das "causas" como a hipótese diferencial poderão ter conseqüências importantes na direção do tratamento e em especial na escuta dos pais.

\section{ORGANOGÊNESE X PSICOGÊNESE: O PON- TO DE VISTA DA PSICANÁLISE}

Não se pode negar que um bebê seja antes de mais nada um feixe de nervos. Serão bem-vindas todas as experiências que puderem avançar no conhecimento das bases neurológicas de todas as patologias precoces do desenvolvimento. Embora absolutamente nada de conclusivo tenha surgido a partir da pesquisa neurológica - a síndrome do X frágil, por exemplo, não é assinalada como causa definitiva do autismo nem mesmo entre os neurologistas ${ }^{1}-$, pode-se sem dúvida falar de uma suscetibilidade ou de vulnerabilidade de origem genética (Laznik, 1994).

Nãoé esse, porém, o ponto decisivo do debate, já que haverá patologias do desenvolvimento cuja origem nunca esteve em uma disfunção neurológica de qualquer natureza. $\mathrm{O}$ psicanalista não descarta a hipótese biológica, mas recusa a discussão posta em termos de uma dicotomia biológico/psíquico. A origem não está nem em um, nem em outro domínio, como diz Alfredo Zenoni (1991):

"Basta reler os Trêsensaios sobre a sexualidade, por exemplo, para constatar até que ponto Freud exclui ao mesmo tempo o fator constitucional e o fator ambiental do plano que é pertinente 
para a explicação da psicopatologia humana. Para Freud, o plano que é pertinente para a causalidade da psicose, da neurose e da perversão não é o plano do desenvolvimento, mas um outro, prévio ao da interação (...). Lacan chama-o às vezes de lugar do Outro, às vezes de ordem simbólica. (...) Ele opera logo na entrada, desde o começo, antes de qualquer interação com o ambiente" (Zenoni, 1991, p.104-5).

Tampouco a hipótese de integrar as duas determinações - o biológico e o psíquico-pode ser aceita pela psicanálise, a partir de uma proposta epistemológica híbrida. A psicanálise tem demarcado claramente a irredutibilidade do discurso médico ao discurso psicanalítico. Clavreul (1983), em $A$ ordem médica, afirma que "toda tentativa de fazer uma reconciliação superficial entre psiché e soma nãoé senão denegação do que instaurou a objetivação científica: a impossibilidade de deixar um lugar que seja para a questão do Sujeito".

O conceito de permeabilidade biológica ao significante busca superar a tentativa de hibridismo, e é uma tentativa de sustentar ao mesmo tempo a consideração de uma base material e sua abertura ao significante, estrutura sem a qual o corpo do bebê não poderá vir a organizar-se como corpo erógeno.

"Parece-nos pertinente aqui um conceito do qual se nota a falta e que não encontramos em outro lugar. Algo que poderíamos chamar de permeabilidade biológica ao significante. Precisamente, S. Freud nos demonstra que a permeabilidade à variação infinita dos representantes de objeto no ser humano reside na ausência de inscrição instintiva prévia do objeto. O conceito que propomos aqui está no reverso desta idéia freudiana. Aparece como um obstáculo à inscrição dessa variação infinita, porque, além da ausência de inscrição genética do objeto, se manifesta 
uma ausência de capacidade de registro do sistema nervoso. Nas crianças autistas, encontramos causas que repousam nesta falta de permeabilidade (...)" (Jerusalinsky, 1989, pp.47-8).

Considerando-se a perspectiva teórica exposta até aqui, o autismo não seria nem o efeito de uma falha genética, nem o efeito de "interações ambientais" entendidas como o faz a psicologia americana, mas uma conseqüência da falha no estabelecimento da relação com o Outro, quer porque o Outro materno não esteve disponível, quer porque falhou no bebê a permeabilidade biológica ao significante.

Seja como for, o corpo de um bebê jamais sairá de sua condição de organismo biológico se não houver para ele um outro que sustente o lugar de Outro Primordial e que o pilote em direção ao mundo humano, que lhe dirija os atos para além dos reflexos, e, principalmente, que thes dê sentido.

Dessa perspectiva, uma criança com graves problemas neurológicos enfrentará, talvez, sérias dificuldades para encontrar um piloto capaz de fazer-lhes face. Mas se verá também em sérias dificuldades se, ainda que "sã", não encontrar quem o introduza na ordem simbólica.

\section{AUTISMO: UMA CRIAÇÃO MODERNA?}

A consideração de que o autismo seja a conseqüência de uma falha no estabelecimento da relação com o Outro abre ainda uma terceira via de reflexão, que ultrapassa a dicotomia orgânico/psíquico. Trata-se de considerar a dimensão da cultura e o valor de uma certa determinação discursiva em circulação no mundo contemporâneo incidindo sobre o autismo. Em outras palavras, há autores para quem o autismo seria uma criação moderna. 
Em um dos pólos dessa polêmica, há, em primeiro lugar, aqueles autores para quem os autistas sempre existiram. Atestam-no as crianças-fada das lendas irlandesas, crianças cujas almas eram furtadas por duendes e que adquiriam os traços cuja descrição os aproxima daquilo que hoje chamamos de autistas. $\mathrm{Na}$ literatura, também fizeram aparições esporádicas, de acordo com Rosenberg (1991). Não se conhecem outros rastros dessas crianças, que provavelmente se confundiam com as débeis, ou então eram submetidas, por exemplo, à eutanásia, como se fazia na Grécia antiga com as crianças deficientes.

No pólo oposto, encontra-se, por exemplo, Volnovich (1993), para quem o autismo seria uma criação moderna sem precedentes na história da humanidade. Ele afirma:

"As contradições e paradoxos da modernidade colocam a infância num lugar de testemunha, onde seus sintomas, incluída a loucura, falam muito menos de um avatar psicopatológico e muito mais de uma produção conflitiva da liberdade" (p.33).

"Produção conflitiva de liberdade" é, para Volnovich, a expressão que resume o mal-estar contemporâneo. É o que resulta de uma representação social da infância na sociedade moderna, marcada por uma reafirmação narcisista e por um ocultamento do sentido da história do sujeito por meio de uma pseudo-informação oferecida pela educação. Assim, para ele a produção da loucura tem raízes sobretudo histórico-políticas.

Uma terceira tese, porém, poderia resolver a aparente contradição entre as duas anteriores. Para essa última, o autismo será um significante moderno que dá nome a um fenômeno estrutural na constituição do sujeito, nome esse que o representa, porém, dentro de uma particular inflexão do discurso social contemporâneo, e que, ao representálo, o recria.

O autista de hoje não é o mesmo que poderia ter surgido no mundo antigo, porque esse nome moderno, criado por Kanner, recorta e cria um novo discurso que o situa e lhe dá lugar no mundo contemporâneo. Cria, com o poder de criação do significante, um novo autista. Que prolifera, vai à mídia, aos filmes, que enternece. Significa algo para a sociedade hoje, e é por ela significado a partir das modelizações sociais à sua disposição.

O autismo de Kanner nasceu em estreita conexão com a culpabilização das mães. Ele ousara comentar que as mães das crianças pareciam frias e distantes, insinuando que talvez isso pudesse relacionar-se também com os problemas de contato daquelas crianças. Ou seja, Kanner oscilou, no transcurso de seus textos, entre considerar a dimensão do orgânico na etiologia do autismo - uma síndrome genética - e enfatizar as relações mãebebê para explicá-lo.

As observações de Kanner espalharam-se como um rastilho de pólvora pelo mundo do pós-guerra, e muito particularmente no seio da cultura americana, na qual trabalhou. Em primeiro lugar, a palavra "fascinante" não veio à toa em sua pena. O mundo já parecia estar preparado e mesmo aguardando o recorte que Kanner acabara de criar. E fascinou-se. O autismo ganhou rapidamente as revistas, o cinema e, mais tarde um pouco, a literatura. A criança autista ganhou status de avis rara; atiçava a curiosidade, mas era ao mesmo tempo escondida pela mãe.

Mas Kanner não causou apenas fascínio. Provocou também o repúdio das mães de autistas, que protestaram contra a idéia de que eram "frias". "Amamos nossos filhos", elas diziam, 
"e ninguém tem o direito de dizer que somos culpadas pelo autismo de nossos filhos." Organizaram-se em associações e puseram-se a lutar por direitos. Kanner teve de recuar, e, em 1946, escreveu Em defesa das mães. Parecia não saber mais o que fazer com sua observação sobre as mães.

Então é necessário repor a questão, afirmando que as mães têm razão - e Kanner também. De fato, é preciso esclarecer: não são as mães reais, com seus sentimentos, sua devoção, sua encarnação em um papel social que exercem bem ou mal, que estão na base da eclosão do autismo infantil precoce. São as mães postas no exercício de uma função que desconhecem exercer, e na qual deveriam apostar, mas não apostam.

Assim, as mães não são culpadas, mas responsáveis pelo destino subjetivo de seus filhos. Entenda-se aí a mãe em posição de Outro materno, atravessada pela articulação entre a sua fantasmática e sua posição de falada pelo discurso social, e que tem diante de si um bebê que se apresenta com uma materialidade que não pode ser negada.

Ora, as mães pós-Kanner foram, ao contrário do que poderia sustentar o discurso da psicanálise, convenientemente "desculpabilizadas" e "desresponsabilizadas" pela sociedade de massas, interessada em fazê-las deixar seus filhos em creches e diante da televisão para correr atrás de novos valores fálicos no mundo do consumo. O agente da "desculpabilização" é a psiquiatria biológica, que atende perfeitamente bem a esses interesses, mais ideológicos do que científicos.

Isso é a criação moderna. Nas histórias das crianças-fada, as mães tinham de cuidar para que seus filhos não fossem roubados. Hoje, porém, não há lugar para responsabilidades. $\mathrm{O}$ autista moderno da mídia e dos psiquiatras não é filho de uma falha na responsabilidade de suas, mães e, no entanto, cura-se com o carinho e a dedicação delas. Ora, o remédio adotado não revela justamente a causa da doença? A sociedade moderna vê no autista a denúncia de sua falha, a denúncia do modo como está tratando suas crias. Choca mais do que a infância abandonada, embora a balança numérica penda muito mais para o lado dos meninos de rua do que para o lado dos autistas.

O autista não poderá deixar de sofrer os efeitos desse lugar moderno em que está situado. Sofre os efeitos dessa significação social, carrega a exclusão da linguagem e da circulação social, submetido a técnicas de condicionamento para permanecer aí, na borda, lugar em que ele, de forma surpreendente, se equilibra.

Há, portanto, uma estrutura autista reveladora de uma especial posição subjetiva na linguagem (ou quem sabe, de uma posição a-subjetiva na linguagem), mas há também o significante "autismo", cunhado pelo social, que recria essa estrutura, tendo efeitos sobre o modo como essa criança é apresentada por seus pais, e sobre o modo como é tratada. 
Assim, não basta saber que o autismo, falha na relação com o Outro, foi determinado genética ou psicogenicamente neste ou naquele caso. Será preciso levar em conta que os pais que o trazem também sofrem os efeitos do significante autismo em circulação social. Mais que isso, será preciso saber que seu filho autista terá sido objetalizado pelo discurso médico. As instituições de tratamento, também capturadas por essa inclinação discursiva, buscarão treiná-lo, adestrá-lo, fazer Teacch com eles. O psicanalista, cuja ética o leva a trabalhar para a emergência do sujeito que não pôde advir no autista, verá crescer a sua responsabilidade diante de todos esses obstáculos.

Diante do discurso médico, o psicanalista deverá demonstrar que é sensato o suficiente para não desconsiderar o corpo em sua dimensão de limite, e não de causa, mas precisará sustentar a posição segundo a qual não haverá corpo se não houver sujeito. E precisará sustentá-la sobretudo diante dos pais dos autistas. Assim, esse posicionamento teórico terá conseqüências éticas no tratamento do autista.

\section{DIFERENCIAL PSICOSE/}

\section{AUTISMO}

Sob a rubrica "psicose e autismo infantil", que designa o diagnóstico dos transtornos graves dentro do referencial psicanalítico, encontram-se estudos de autores como Melanie Klein (192145; 1932) e Frances Tustin (1984). Na esteira do pensamento de Jacques Lacan, situam-se Maud Mannoni (1977; 1979; 1987), Françoise Dolto (1972; 1985), Rosine e Robert Lefort (1984). No entanto, tal profusão ainda não é suficiente para que se tenha uma definição precisa das diferentes manifestações dessas patologias. Mais do que isso, não há um consenso sobre a ne- 
cessidade de instituir-se uma estrutura clínica, separada da psicose infantil, para designar o autismo.

Melanie Klein diagnosticou como esquizofrênico o célebre Pequeno Dick, quando, de acordo com sua descrição, ele talvez recebesse hoje o diagnóstico de autismo (citado por Ledoux, 1989). Isto mostra o desacordo em que se encontravam e ainda se encontram os psicanalistas a respeito dessas diferenças diagnósticas.

"Há evidentemente diferenças radicais", afirma Ledoux, "entre o autismo infantil precoce e outras formas menos severas de psicoses. Diferenças no nível do funcionamento mental, dos mecanismos em jogo. Alguns hesitam em pôr o autismo precoce severo sob a mesma rubrica estrutural que outras formas de psicose, e podemos nos perguntar também se, no plano etiopatogênico, estamos lidando com a mesma coisa, com os mesmos 'fatores'. Para outros, não há sentido em isolar o autismo infantil" (p.333-4).

Rocha (1997) e seu grupo de trabalho preferiram abordar todas as patologias infantis sob a rubrica de "autismos". Ela explica:

"Durante muito tempo utilizávamos, no Centro de Pesquisa em Psicanálise e Linguagem (CPPL), o termo psicose infantil precoce englobando autismo e psicose simbiótica. Neste trabalho" - referindo-se aqui ao livro que o CPPL publicou em 1997 - "usaremos o termo autismo para denominar estas duas patologias, na medida em que se distinguem de todas as outras patologias da infância" (p.16).

Atualmente, os esforços dos psicanalistas vêm se concentrando na direção de definir dois quadros distintos para o autismo e a psicose.

Jerusalinsky (1993) marca radicalmente a diferença, e propõe que se entenda o autismo como uma quarta es- 
trutura clínica, ao lado das três outras - psicose, neurose e perversão - propostas por J. Lacan. Em entrevista concedida à revista da Associação Psicanalítica da Porto Alegre, Jerusalinsky responde do seguinte modo quando indagado se a psicose e $\mathrm{O}$ autismo são ou não estruturas diferentes:

"No que se refere à lógica que articula a posição do sujeito a respeito do significante, eu diria que entre psicose e autismo não há nenhuma identidade de estrutura, porque num caso se trata da forclusão e no outro se trata da exclusão. É evidente que no campo lacaniano não há unanimidade neste ponto, porque há quem considere (segundo a lógica que tome como referente) a exclusão como um caso particular da forclusão, mas esse não é o meu ponto de vista. A diferença entre forclusão e exclusão consiste em que, no caso da forclusão, se produz uma inscrição do sujeito numa posição tal, que esta inscrição não pode ter conseqüiências na função significante. No caso da exclusão, não há inscrição do sujeito; no lugar em que a inscrição deveria se encontrar, se encontra o Real, ou seja, a ausência de inscrição. Esta diferença radical de estrutura conduz a efeitos clínicos observáveis" (p.63).

A afirmação de que não há inscrição se opôe radicalmente às interpretações clássicas da psicanálise a respeito do autismo, para as quais teria havido o recuo do "sujeito" diante de experiências traumáticas na relação com o Outro primordial. São as bolhas, as conchas autísticas, que supõem um sujeito prévio, capaz de "avaliar" a hostilidade do mundo e "escolher" a fuga.

Para a psicanálise de inspiração lacaniana, não há como supor a existência de um sujeito prévio, já que, para Lacan, o sujeito é efeito da operação significante, efeito da instalação da linguagem. A anterioridade de um sujeito não é posta pelo teórico, mas o é pelo Outro materno. Essa é a resposta ao aparente paradoxo de que o sujeito se faz na e pela linguagem, mas ao mesmo tempo precisa contar com algo da ordem de uma estrutura subjetiva que o guie "para dentro" da estrutura da linguagem. O Outro materno supõe o que não está, e antecipa a função-sujeito como forma de fazê-la funcionar antes de estar instalada, e permitir então seu advento a partir da travessia das estruturas de linguagem.

Assim, em uma etapa precocíssima, na qual a operação significante não se instalou ainda, não pode haver um sujeito recuando diante da hostilidade do mundo.

A hipótese lacaniana é então a de que as marcas, as inscrições originárias, não se alçam à condição de significantes com pleno poder de linguagem. As primeiras marcas, que deveriam passar por diferentes tempos para se constituírem como marcas eficazes e capazes de produzir o sujeito, sofrem uma espécie de aborto. Começam a sua aventura em direção ao mundo da lin- 
guagem, mas não chegam lá, por falta de quem signifique essas marcas como marcas significantes, e de quem lhes dê certa regularidade de leitura. Por isso, muitas vezes não se percebem os autistas nos primeiros meses. Podem surgir as imitações, que não têm ainda valor cabal de organização de linguagem - a criança pode dar "tchauzinho", por exemplo-, sem que isso venha a adquirir todo o enraizamento lingüístico e de traço na relação com o Outro; então, desaparecem tempos depois sem deixar rastro. Eis por que se afirma que o autista está fora da linguagem: o que poderia ter sido marca de linguagem deixou de sê-lo. Como diz Laznik (1997), as estereotipias - para as quais recuam algumas imitações que não se transformaram em identificações - são ruínas de antigos castelos, de significantes que deixaram de sê-lo, e que por isso nunca o foram de fato.

Pode-se afirmar, como o faz Vinheiro (1995), que "no autismo, não encontramos a primeira identificação, ao pai, e nem a segunda identificação, ao traço (...). Na psicose, já haveria essa primeiríssima identificação. Aliás, a psicose trabalha sobre essa problemática. O psicótico está, o tempo todo, referindo-se a essa dimensão - a do pai. Mas a questão do traço unário, que leva à identificação secundária e abre à questão do desejo, é complexa" (p.157). Segundo essa autora, não se pode falar em traço unário na psicose: se a falta de objeto é condição de instalação do traço, e se na psicose o objeto não falta, disto decorre que não haverá instalação do traço.

Isto não significa, porém, que o autista não tenha algo a dizer:

"[O discurso analítico] é o único discurso que pode escutar o que o autista tem a dizer. E questionar o seu consentimento à estrutura que o aprisiona. Pois a suposta passividade do 
autista mascara a rejeição ativa do Outro que está no cerne de sua posição. A criança autista, excluída do Outro da palavra, goza e ainda sustenta, sem sabê-lo, o sofrimento e a angústia de seu entorno" (Vidal \& Vidal, 1995, p.117).

A partir dessa discussão em torno do diagnóstico diferencial entre a psicose e o autismo, adota-se aqui, em resumo, a seguinte posição teórica, advinda de uma das direções possíveis abertas pelo ensino de Lacan: o autista está fora do campo da linguagem, enquanto o psicótico está na linguagem, mas fora do discurso.

Mais do que uma afirmação de que a exclusão de nada ajudará o autista, esta é uma referência teórica que pode ser de grande valor na direção do tratamento do autista.

A operação clínica consistirá, nesses casos, em ir buscar esses restos de marcas que não se "significantizaram", para, a partir delas, buscar reintroduzir a operação significante. Como? Fazendo exatamente o que a mãe, seja por que for, não fez. Supondo um sujeito. Em termos clínicos, essa operação não difere daquela do psicanalista "tustiniano". Esse último entende ter havido no início um sujeito que recuou, o que o faz operar, portanto, com base na suposição de um sujeito. Mas os fundamentos teóricos são diferentes, e as interpretações também. O autista que balança incessantemente a cabeça poderá ser interpretado por um psicanalista "tustiniano" como um sujeito que está dizendo "não", que está se recusando a entrar no mundo humano. $\mathrm{O}$ "lacaniano" dirá que esse é um velho automatismo que se instalou e não significa nada. Mas buscará refazer, com a mãe, uma simbolização produzida a partir de sua fantasmática; esse "não" poderá ser por ela interpretado, por exemplo, com uma observação assim formulada: "Nunca quis me olhar". Uma significação que venha a surgir da posição fantasmática da mãe, e não da leitura do teórico, terá mais chances de produzir algum tipo de inscrição. Tarde demais? É bem possivel, se essa criança já tiver 10 anos. Bem animador, se tiver só um.

Uma outra vantagem na diferenciação da psicose e do autismo está no fato de que, havendo duas estruturas, será possível formular a hipótese de que há passagem de uma para outra, o que explica a fenomenologia peculiar de muitos casos clínicos.

"Uma questão se coloca - se autismo e psicose não são da mesma ordem, por que a tendência geral de situar o autismo como psicose? Talvez porque a psicose seja a saída que ocorre com maior freqüência. Lacan nos dirá: 'Que se trata de fenômenos de ordem psicótica, mais exatamente de fenômenos que podem terminar em psicose, isso não me parece duvidoso" (Vinheiro, 1995, p.158).

Eis o que a clínica faz aparecer: crianças que exibem falhas na especularização ao lado de uma psicose que dá provas de sua estrutura ao vir alicerçada, por exemplo, em fenômenos elementares como a alucinação verbal. São acompanhadas de mães que também exibem a fenomênica clássica da "mãe do psicótico", mas acabam por desvelar, para a escuta do psicanalista, uma posição inicial, ocupada nos primórdios da relação mãe-bebê, bastante oposta àquela com a qual chegaram para o tratamento: uma posição que não lhes permitiu sustentar a especularização de seus bebês. São mães que se apresentam hoje como, digamos, "excessivas", que iniciaram porém seus primeiros movimentos na qualidade de mães "a menos". Na oscilação de mães "poucas" para mães "excessivas", alicerçaram para seus filhos uma subjeti- 
vação que partiu do autismo e rumou para a psicose. O que as levou a essa oscilação resta a formular. O que se pode supor, porém, é que a circulação discursiva em torno da falta de culpa e de responsabilidade das mães não tem ajudado nem um pouco.

Para resumir: um diagnóstico diferencial da psicose e do autismo que supere a dicotomia organogênico/psicogênico, que introduza a incidência do discurso contemporâneo sobre o autismo e que leve em conta a passagem do autismo para a psicose terá conseqüências clínicas sobre a direção do tratamento, em especial sobre a escuta dos pais. Aposta-se que, para eles, fará diferença que um psicanalista oponha resistência à objetalização da criança e à "desresponsabilização" do Outro matemo, pois isto permitirá que se localize com maior precisão a posição das mães, quem sabe a tempo de a reverter.

\section{REFERÊNCIAS \\ BIBLIOGRÁFICAS}

Clavreul, J. (1983). A ordem médica. São Paulo, SP: Brasiliense.

Dolto, F. (1972). Ocaso Dominique. Rio de Janeiro, RJ: Zahar.

(1985). Seminário de psicanálise de crianças. Rio de Janeiro, RJ: Zahar.

Jerusalinsky, A. (1989). Psicanálise e desenolvimento infantil. Porto Alegre, RS: Artes Médicas.

(1993). Psicose e autismo na infância: uma questão de linguagem. Psicose. Boletim da Associação Psicanalítica de Porto Alegre, ano $4, n^{\circ} 9$.

Kanner, L. (1943). Os distúrbios autísticos do contato afetivo. In Rocha, P. (org.). Autismos. São Paulo, SP: Escuta, 1997. (1940). En defensa de las madres. Buenos Aires: Paidós, 1974.
Klein, M. (1921-45). Contribuições àpsicanálise. Rio de Janeiro, RJ: Mestre Jou, 1970. (1932). El psicoanálisis del niño. Buenos Aires: Hormé

Laznik, M.-C. (org.) (1994). O que a clinica doautismopodeensinaraospsicanalistas. Salvador, BA: Ágalma.

_ (1997). Rumoà palaura. São Paulo, SP: Escuta.

Ledoux, M. (1989). Conceptionspsychanalitiques des psychoses infantiles. Paris: PUF.

Lefort, R. \& Lefort, R. (1984). Nascimento do Outro. Salvador, BA: Fator.

Mannoni, M. (1977). Educação impassúvel. Rio de Janeiro, RJ: Zahar.

- (1979). Un lieu pourvivre. Paris: Seuil.

(1987). A criança, sua "doença"e os outros. Rio de Janeiro, RJ: Guanabara.

Postel, J. \& Quétel, C. (org.) (1993). Historia de la psiquiatria. Cidade do México: Fondo de Cultura Económica.

Rocha, P. (1997). Autismos. São Paulo, SP: Escuta.

Rosenberg, R. (1991). Autismo: histórico e conceitoatual. Temas sobre desenuobimento, ano $1, \mathrm{n}^{\circ} 1, \mathrm{p} .4-7$.

Tustin, F. (1984). Estados autísticos em crianças. Rio de Janeiro, RJ: Imago.

Vidal, E. \& Vidal, M. C. (1995). O que o autista nos ensina: considerações sobre a alienação. Letra Freudiana, ano XIV, $n^{\circ} 14$, p.117-38.

Vinheiro, V. (1995). Autismo e psicose. Letra Freudiana, ano XIV, $\mathrm{n}^{\circ} 14, \mathrm{p} .151-57$.

Volnovich, J. (1993). A psicose na criança. Rio de Janeiro, RJ: Relume-Dumará.

Zenoni, A. (1991). "Traitement" de l'Autre. Préliminaire. Bruxelas, Antenne 110, $\mathrm{n}^{\circ}$ 3, p.101-12.

\section{NOTA}

1 Cf. Schwartzman, Salomão. Autismo infantil. São Paulo, SP:Mennon, 1995.

Recebido em 11/99 